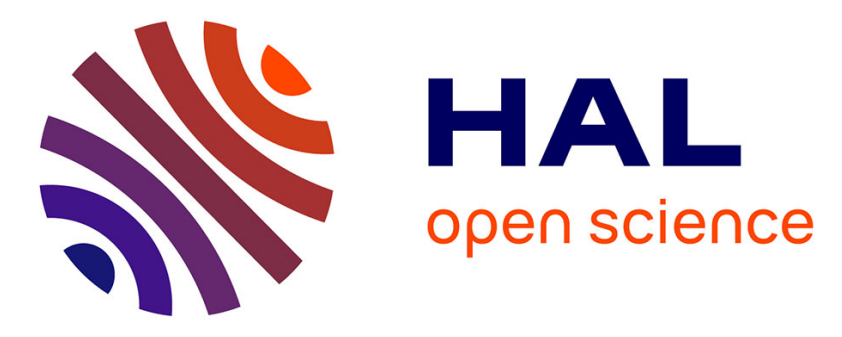

\title{
Hygrothermal effects and moisture kinetics in a bio-based multi-layered wall: Experimental and numerical studies
}

N. Reuge, F. Collet, S. Pretot, S. Moissette, Marjorie Bart, O. Style, A. Shea, C. Lanos

\section{To cite this version:}

N. Reuge, F. Collet, S. Pretot, S. Moissette, Marjorie Bart, et al.. Hygrothermal effects and moisture kinetics in a bio-based multi-layered wall: Experimental and numerical studies. Construction and Building Materials, 2020, 240, pp.117928. 10.1016/j.conbuildmat.2019.117928 . hal-02443601

\section{HAL Id: hal-02443601 \\ https://hal-univ-rennes1.archives-ouvertes.fr/hal-02443601}

Submitted on 17 Feb 2020

HAL is a multi-disciplinary open access archive for the deposit and dissemination of scientific research documents, whether they are published or not. The documents may come from teaching and research institutions in France or abroad, or from public or private research centers.
L'archive ouverte pluridisciplinaire HAL, est destinée au dépôt et à la diffusion de documents scientifiques de niveau recherche, publiés ou non, émanant des établissements d'enseignement et de recherche français ou étrangers, des laboratoires publics ou privés. 
Hygrothermal effects and moisture kinetics in a bio-based multi-layered wall: Experimental and numerical studies

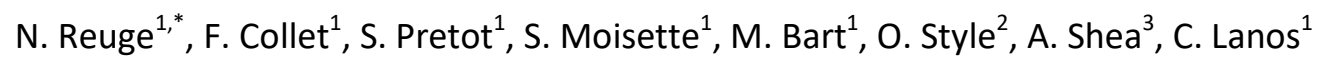

${ }^{1}$ Université de Rennes, Laboratoire de Génie Civil et Génie Mécanique, Axe Ecomatériaux pour la construction, 3 rue du Clos Courtel, BP 90422, 35704 Rennes, France

${ }^{2}$ PROGETIC, Ramon Turró 100-104, 5-7, 08005 Barcelona, Spain

${ }^{3}$ Department of Architecture \& Civil Engineering, BRE Centre in Innovative Construction Materials, University of Bath, United Kingdom

*Corresponding author, reuge@free.fr - phone: +33 6019015 78, ORCID: 0000-0003-4764-990X

\begin{abstract}
A bio-based multi-layered reference wall has been developed within the framework of the European ISOBIO project. One of the key points of this project was to be able to perform proper simulations of the hygrothermal transfers occurring inside such walls. Previous published investigations, also performed in the framework of this project, have demonstrated that the classic assumption of instantaneous equilibrium between local relative humidity and water content according to the sorption isotherm is not relevant for bio-based porous materials, where, in practice, a rather slow kinetics of sorption occurs. The theoretical background developed in this previous study is used here to determine the kinetic constants of the bio-based construction materials and to perform 1D hygrothermal simulations. The kinetics constants are determined thanks to a 1D cylindrical tool based on the local kinetics approach, validated against several experiments of sorption. Then, heat and hygric transfers recorded on a demonstrator building (The HIVE, Wroughton, UK) are analyzed and are simulated using two modeling tools: TMC based on the Künzel approach and TMCKIN based on the local kinetic approach. From the simulations, the local kinetics improves the small timescale $R H$ dynamics. The comparison with measurements performed in the demonstrator confirms the relevance of the local kinetics approach.
\end{abstract}

\title{
Keywords
}

Bio-based building materials; Local kinetics; Sorption; Hygrothermal transfer; Mass transfer; Modeling

\section{Introduction}

The aim of the European ISOBIO project was to develop multi-layered wall solutions made of biobased materials featuring very low carbon footprints and high insulating properties. The present study has been done in this framework. One of the key points of this project was to be able to perform proper simulations of the hygrothermal transfers occurring inside the ISOBIO reference wall.

Sorption of water in porous media involves interdependent phenomena such as vapor / liquid water mass transport by Fickian diffusion and equilibrium isotherms of sorption also called "water storage functions" associated with hysteretic phenomena. The diffusion coefficients can be determined in 
steady state exchange by permeability measurements (i.e. "wet cup method" [1]). The equilibrium isotherms of sorption can be determined by gravimetric methods [2]. Actually, the equilibrium water contents evolve as a function of the relative humidities between the main adsorption and desorption equilibrium isotherms depending on the material's hygric history and this complex phenomenon can be described by hysteretic models [3,4]. Note that heat and mass transfer phenomena have to be properly modeled and coupled, as highlighted in [5]: heat transfers in walls can have a significant effect on the hygric transfers and inversely. But despite the reliability of these models, it seems that inside some porous materials, and particularly in bio-based materials, simulations largely underestimate the time required for the water content to reach the equilibrium: this has been established for bio-based materials in $[6,7,8]$ and by Reuge et al. [9], but also for more traditional material such as cement compounds or concretes [10,11,12]. These considerations take on their full meaning in the cases of hygrothermal transfers with permanent fluctuations such as in materials of building envelopes, in soils or in food materials.

Classic simulation tools predicting hygrothermal transfers in building materials are based on the assumption that for a given local relative humidity $\varphi$, the associated equilibrium local water content $w$ is reached instantaneously. In our previous studies $[9,13]$, three hemp-lime concretes were studied and it was demonstrated that such an assumption led to serious inconsistencies. Thus, as reported in the aforementioned literature, our previous studies have established that a local kinetics of sorption exists (from water vapor to liquid water and inversely) which can be slow compared to the diffusive fluxes. Obviously, this invalidates the classic assumption.

The first part of this study deals with the classic hygric and thermal properties obtained from characterizations performed on samples of ISOBIO materials. From the knowledge of these classic properties, a simple steady-state sensitivity study is performed to determine the most sensitive layers in the ISOBIO reference wall in term of thermal transmittance and resistance to water vapor diffusion. Then, the theoretical background necessary to model the water sorption / kinetics of sorption is presented, relying on the study [9]. Thanks to this theoretical background, the kinetics constants of some of the studied ISOBIO materials are determined numerically and analytically by adjustments on sorption experiments. The last part of this study compares the results of the hygrothermal simulations based on the classic model with and without taking into account solar radiation and the local kinetics model to the measurements performed inside the ISOBIO reference wall at the HIVE demonstrator (Wroughton, UK) over a wide range of hygric and thermal operating conditions.

\section{Classic hygrothermal properties of the ISOBIO materials}

\subsection{Reference ISOBIO wall}

The reference ISOBIO wall is composed of: a $B C^{T M}$ lime-hemp render (BCB), a CAVAC ${ }^{T M}$ Rigid insulation panel made of hemp shiv and an organic binder (CAV), a Biofib Trio flexible insulation panel from CAVAC ${ }^{\text {TM }}$ made of hemp flax and cotton (BIO), an OSB3 panel, a Proclima ${ }^{\text {TM }}$ INTELLO membrane (INT), a Lignicell CSB $^{\text {TM }}$ panel made of compressed straw (CSB) and a CLAYTEC ${ }^{\text {TM }}$ clayhemp plaster (CLA). Note that this wall is supported by a timber frame which will not be considered in the simulations. The configuration and the thicknesses of the different layers are given in Figure 1.

Note that the local hygric variables given at the macroscopic scales will be written as lower case letters (e.g. the local water content $w$ ) while the hygric variables given at the sample scales will be written as upper case (e.g. the global water content $W$ ). 


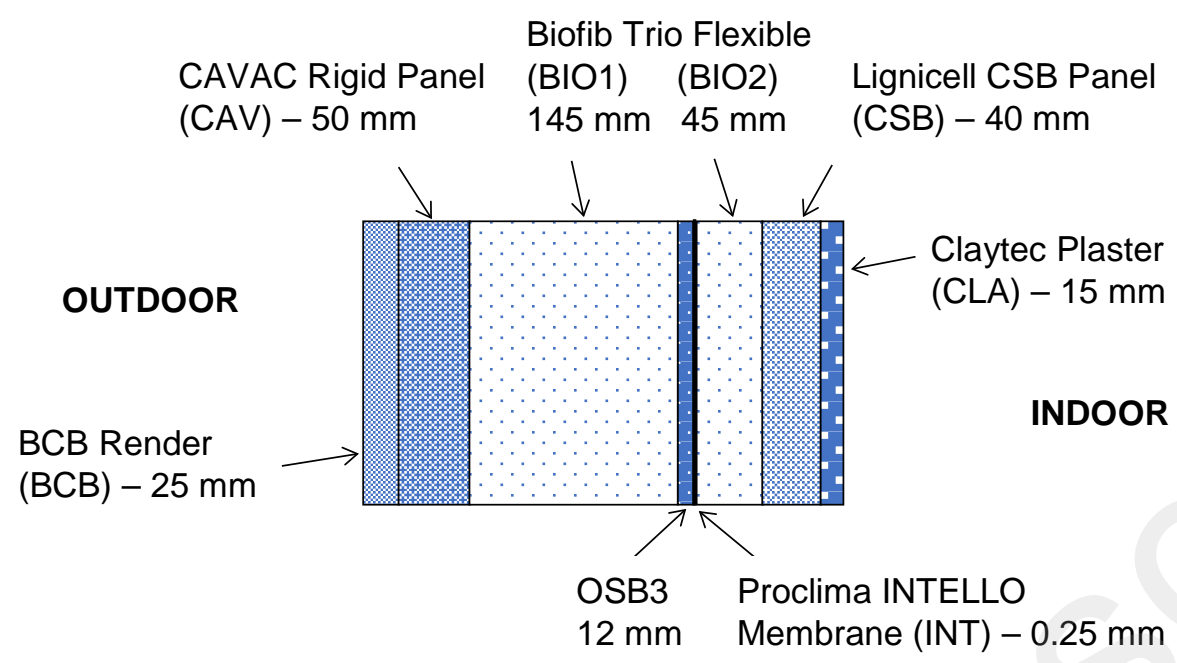

Figure 1: ISOBIO reference wall

\subsection{Experimental characterizations}

The experimental characterizations of the ISOBIO materials hygrothermal properties have been performed by Collet et al. [14]. Therefore, the experimental methods of measurement will not be described here but only the values of the properties necessary to perform the simulations.

Table 1 is a compilation of the following properties measured at a temperature of $23^{\circ} \mathrm{C}$ : the bulk densities at dry state $\rho_{0}$, the porosities $\varepsilon_{0}$, the vapor diffusion resistance factors at dry state $\mu_{0}$, the thermal conductivities at dry state $\lambda_{0}$ and the specific heat capacities at dry state $C p_{0}$. Note that while most of these properties have been determined by Collet et al. [14], a few others have been determined by other ISOBIO partners (University of Bath for BCB permeability) or obtained from trustable technical sheets.

The adsorption behavior of representative samples of the ISOBIO materials (CAV, BIO, OSB3 and CSB) have been studied in [14]: they have measured their water content $W\left(\mathrm{~kg}\right.$ of water per $\mathrm{m}^{3}$ ) temporal evolutions until quasi stabilization (or in other words, their global kinetics of adsorption) after several instantaneous increments of ambient relative humidity $R H$ at a temperature $T$ of $23^{\circ} \mathrm{C}$. The final stabilized $W$ are actually the equilibrium water contents $W_{e q}$ at the corresponding $R H$, allowing to determine the adsorption isotherms of the materials. The moisture storage functions of the other ISOBIO materials come from technical sheets and/or F-IBP databases (BCB, INT and CLA). The data are shown in Figure 2.

\subsection{Models of properties}

From the collected data of $W_{e q}$ as a function of $R H$, the Van Genuchten model VG [15] has been used to model the adsorption isotherms. Note that the VG model is claimed valid even at high $R H(>90 \%)$. It is expressed as follow:

$$
W_{e q}(R H)=W_{\text {sat }}\left[1+(-h \ln (R H))^{\eta}\right]^{1 / \eta-1}
$$

where $h$ and $\eta$ are adjustment coefficients. 


\begin{tabular}{|c|c|c|c|c|c|}
\hline & $\begin{array}{c}\rho_{0} \\
\pm 5 \% \\
\left(\mathrm{~kg} \cdot \mathrm{m}^{-3}\right)\end{array}$ & $\begin{array}{c}\varepsilon_{0} \\
\pm 5 \% \\
(-)\end{array}$ & $\begin{array}{c}\mu_{0} \\
\pm 10 \% \\
(-)\end{array}$ & $\begin{array}{c}\lambda_{0} \\
\pm 5 \% \\
\left(\mathrm{~W} \cdot \mathrm{m}^{-1} \cdot \mathrm{K}^{-1}\right)\end{array}$ & $\begin{array}{c}C p_{0} \\
\pm 10 \% \\
\left(\mathrm{~J} \cdot \mathrm{kg}^{-1} \cdot \mathrm{K}^{-1}\right)\end{array}$ \\
\hline BCB & 530 & 0.546 & 9 & 0.13 & 1006 \\
\hline CAV & 190 & 0.874 & 11 & 0.07 & 2100 \\
\hline BIO & 26.5 & 0.98 & 3.6 & 0.039 & 1800 \\
\hline OSB3 & 551 & 0.609 & 138 & 0.13 & 1600 \\
\hline INT & 85 & 0.085 & $1.364 .10^{5}$ & 2.4 & 2500 \\
\hline CSB & 449 & 0.72 & 27 & 0.10 & 1700 \\
\hline CLA & 1392 & 0.294 & 10 & 0.62 & 1040 \\
\hline
\end{tabular}

Table 1: ISOBIO materials properties at dry state at $T=23^{\circ} \mathrm{C}$

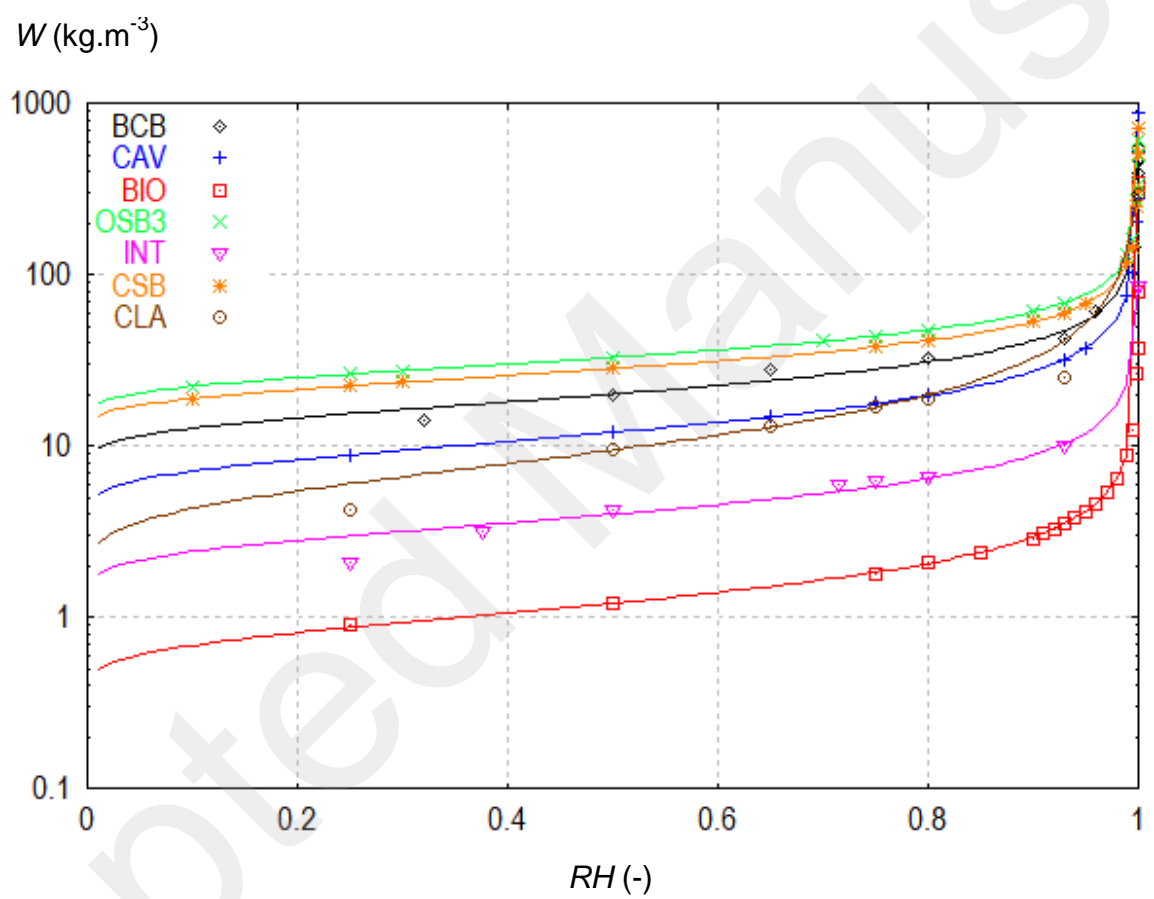

Figure 2: Isotherms of adsorption of the ISOBIO materials - Experimental data (symbols) and adjustments with the VG model

This VG model has been adjusted on the experimental data for each ISOBIO material. These adjustments have been performed to obtain the best possible correlations in the range of $40 \%$ $100 \% R H$. The values of the adjustment coefficients are given in Table 2 and the Figure 2 shows the adjustments. Note that the maximum water contents $W_{\text {sat }}$ have been considered equal to the measured porosities $\varepsilon_{0}$ multiplied by the liquid water density (i.e. $1000 \mathrm{~kg} \cdot \mathrm{m}^{-3}$ ) excepted for BIO.

The evolutions of the vapor diffusion resistance factors $\mu$ as a function of the local water content $w$ or $R H$ have been ignored except for the Proclima INTELLO membrane because it is a hygrovariable material evolving very significantly as a function of $R H$. The data provided by Proclima/F-IBP have 
been fitted by a logistic power as shown in Figure 3. Because of its great values, this parameter must be carefully modeled. Note that at $100 \% R H, \mu$ decreases to 553 .

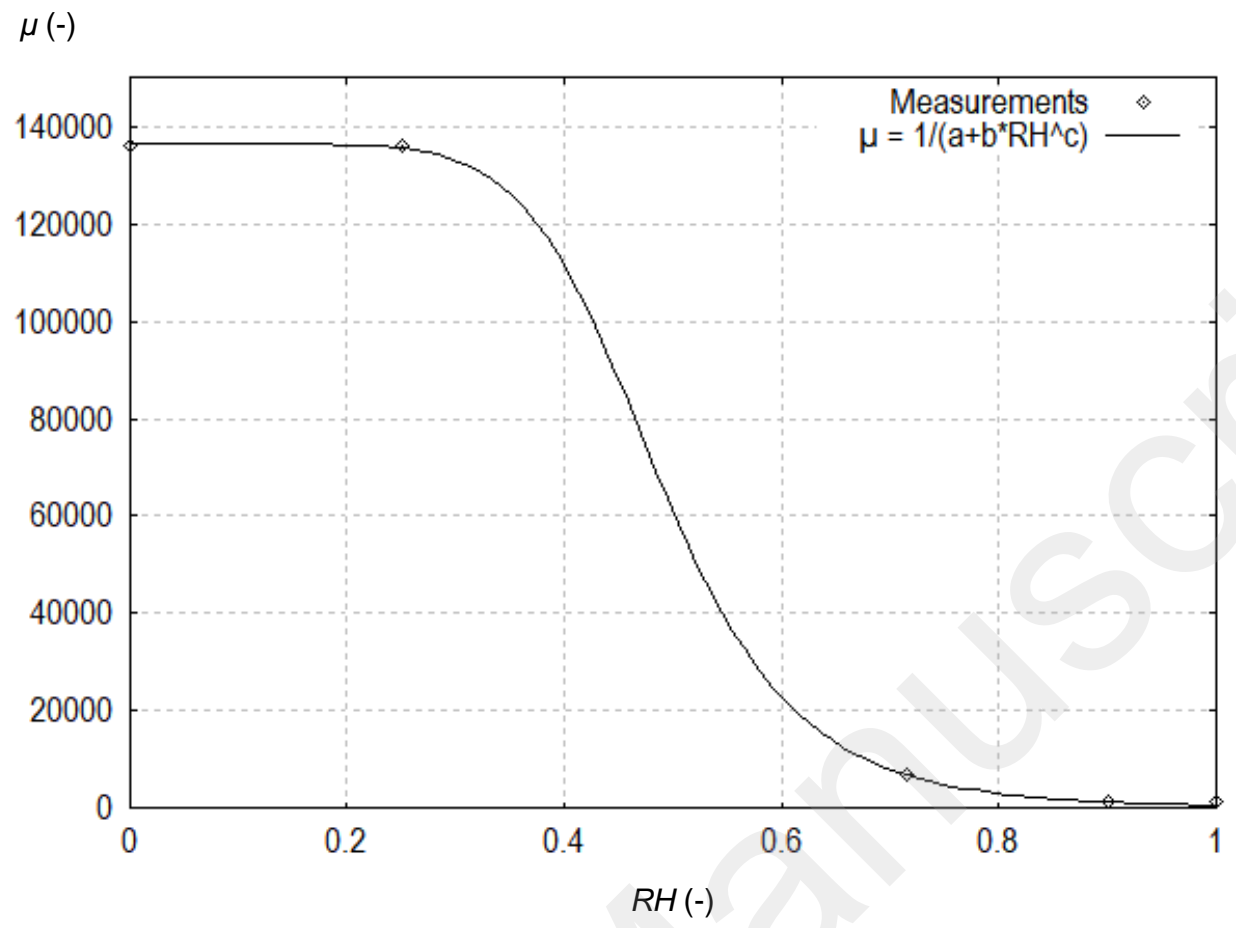

Figure 3: Vapor diffusion resistance factors $\mu$ of the Proclima INTELLO membrane as a function of $R H$ - Measurements (points) and adjustment by a logistic power law $-\mathrm{a}=7.3310^{-6}, \mathrm{~b}=1.8 .10^{-3}$ and $\mathrm{c}=$ 7.644

Finally, the evolution of the thermal conductivities as a function of the water content has been modeled by the self-consistent scheme [16], which takes the following expression:

$$
\begin{aligned}
\lambda(W)= & \lambda_{s}\left\{1+\varepsilon_{0}\left[\left(1-\varepsilon_{0}\right) / 3+\left(3+\left(W / 1000 \varepsilon_{0}\right)(0.025 / 0.6-1)\right)\right.\right. \\
& \left.\left.\cdot\left(3\left(0.025 / \lambda_{s}-1\right)-\left(W / 1000 \varepsilon_{0}\right)(0.025 / 0.6-1)\left(2 \cdot 0.6 /\left(\lambda_{s}+1\right)\right)\right)^{-1}\right]^{-1}\right\}
\end{aligned}
$$

The coefficient $\lambda_{s}$ (which can be seen as the thermal conductivity of the material skeleton) have been

\begin{tabular}{|c|c|c|c|c|}
\hline & $\begin{array}{c}W_{\text {sat }} \\
\left(\mathrm{kg} \cdot \mathrm{m}^{-3}\right)\end{array}$ & $\begin{array}{l}h \\
(-) \\
\end{array}$ & $\begin{array}{l}\eta \\
(-)\end{array}$ & $\begin{array}{c}\lambda_{s} \\
\left(\mathrm{~W} \cdot \mathrm{m}^{-1} \cdot \mathrm{K}^{-1}\right)\end{array}$ \\
\hline $\mathrm{BCB}$ & 546 & 8524 & 1.38 & 0.312 \\
\hline CAV & 874 & 27490 & 1.435 & 0.53 \\
\hline $\mathrm{BIO}$ & 348 & 228504 & 1.473 & 1.055 \\
\hline OSB3 & 609 & 11360 & 1.325 & 0.367 \\
\hline INT & 85 & 2091 & 1.42 & 2.74 \\
\hline CSB & 720 & 23172 & 1.334 & 0.38 \\
\hline CLA & 294 & 271 & 1.656 & 0.995 \\
\hline
\end{tabular}
adjusted such as $\lambda(W=0)$ equals $\lambda_{0}$. The values of $\lambda_{s}$ are given in Table 2 .

Table 2: Adjustment coefficients - VG model and self-consistent scheme 


\subsection{Sensitivity study}

Based on the materials thermal conductivities $\lambda_{0}$ and the vapor diffusion resistance factors $\mu_{0}$ at dry state, the total thermal transmittance $U$ and vapor resistance $R$ of this wall are of $0.155 \mathrm{~W} \cdot \mathrm{m}^{-2} \cdot \mathrm{K}^{-1}$ and 1.95.10 11 Pa. ${ }^{2}$.s. $\mathrm{kg}^{-1}$ respectively.

Then, by individually varying $\lambda_{0}$ and $\mu_{0}$ of each layer $( \pm 10 \%)$, a sensitivity study has been performed. The sensitivities $S_{U}$ and $S_{R}$ given by eqs (3) and (4) of each layer are reported in Table 3 . This means that if $\lambda_{0}$ or $\mu_{0}$ is modified by $x \%, U$ and $R$ of the wall are modified by $x . S_{U} \%$ or $x . S_{R} \%$ respectively.

$$
\left\{\begin{array}{l}
S_{U}=\frac{U\left(\lambda_{0}+10 \%\right)-U\left(\lambda_{0}-10 \%\right)}{0.2 U\left(\lambda_{0}\right)} \\
S_{R}=\frac{R\left(\mu_{0}+10 \%\right)-R\left(\mu_{0}-10 \%\right)}{0.2 R\left(\mu_{0}\right)}
\end{array}\right.
$$

\begin{tabular}{|c|c|c|}
\hline & $S_{U}(-)$ & $S_{R}(-)$ \\
\hline BCB & 0.03 & 0.01 \\
\hline CAV & 0.115 & 0.027 \\
\hline BIO & 0.77 & 0.03 \\
\hline OSB3 & 0.016 & 0.05 \\
\hline INT & 0.0004 & 0.83 \\
\hline CSB & 0.066 & 0.049 \\
\hline CLA & 0.003 & 0.007 \\
\hline
\end{tabular}

Table 3: Sensitivity study

Regarding $U$, the most sensitive material is obviously the Biofib Trio BIO (which is actually implemented in two layers of a total thickness of nearly $20 \mathrm{~cm}$ and which shows the lowest thermal conductivity) with a $S_{U}$ of 0.77 and, to a much lesser extent, CAV and CSB.

Regarding $R$, the most sensitive material is obviously the membrane INT with a $S_{R}$ of 0.83 and, to a much lesser extent, OSB3 and CSB. Note that the $S_{R}$ of INT is given at dry state and will decrease very significantly with $R H$ as this is a hygrovariable membrane.

Therefore, if the global characteristics of the ISOBIO reference wall need to be modified regarding any standard requirement, this sensitivity study can be of a precious help.

\section{Mass transport governing equations}

In this section, (i) air transport is ignored. In the porous samples, water is present in gaseous form (water vapor) and in liquid form. Therefore, there are two mass balance equations to consider. Assuming that (ii) the convective transport is negligible, they take the following form: 


$$
\left\{\begin{array}{l}
\frac{\partial \bar{\rho}_{v}}{\partial t}-\nabla \cdot\left(D_{p, v} \nabla \bar{\rho}_{v}\right)=-R_{s} \\
\frac{\partial \bar{\rho}_{l}}{\partial t}-\nabla \cdot\left(D_{p, l} \nabla \bar{\rho}_{l}\right)=R_{s}
\end{array}\right.
$$

where $\bar{\rho}_{v}$ and $\bar{\rho}_{l}$ are the local water vapor and liquid water partial densities, $D_{p, v}$ and $D_{p, l}$ are the water vapor and liquid water diffusivities and $R_{s}$ is the rate of sorption.

The local relative humidity can be expressed as follow:

$$
\varphi=\frac{P_{v}}{P_{\text {sat }}}=\frac{\bar{\rho}_{v} R T}{M_{w} P_{\text {sat }}}
$$

and the local liquid water partial density $\bar{\rho}_{l}$ (i.e. the local water content) will be written by convention as $w$. Thus, eqs $(5,6)$ can be rewritten as follow:

$$
\left\{\begin{array}{l}
\frac{\partial\left(\varphi P_{s a t}\right)}{\partial t}-\nabla \cdot\left[\delta_{v, p} \frac{R T}{M_{w}} \nabla\left(\varphi P_{s a t}\right)\right]=-\frac{R T}{M_{w}} R_{s} \\
\frac{\partial w}{\partial t}-\nabla \cdot\left(D_{p, l} \nabla w\right)=R_{s}
\end{array}\right.
$$

where the porous media vapor permeability $\delta_{v, p}=\delta_{v} / \mu=D_{v} M_{w} / \mu R T$, the water vapor diffusion resistance factor being given by: $\mu=\delta_{v} / \delta_{v, p}=D_{v} / D_{p, v}$.

It is commonly assumed that the rate of sorption $R_{s}$ is very fast compared to the vapor diffusive flux leading to the so-called Künzel mass transfer equation [17].

Note that the coupling of eqs $(8,9)$ with a hysteretic model (e.g. [4]) can easily be done: the reversal points (i.e. transitions between adsorption and desorption phases) are obtained when the sign of $R_{s}$ changes.

As demonstrated and validated in the study of Reuge et al. [9] based on three different hemp concretes, the following expression for the sorption rate seems appropriate for the bio-based materials:

$$
R_{s}=k_{0}\left(w_{e q}(\varphi)-w\right)^{2}
$$

where $k_{0}$ is the local kinetic constant of sorption (adsorption or desorption) and $w_{e q}$ is the equilibrium local water content given by the sorption isotherm at a local relative humidity $\varphi$. Note that this is a second order kinetics and consequently the unit of $k_{0}$ is expressed in day $^{-1} /\left(\mathrm{kg}^{-\mathrm{m}^{-3}}\right)$. In [9], the values obtained for the studied hemp concretes are around $1 \mathrm{day}^{-1} /\left(\mathrm{kg} \cdot \mathrm{m}^{-3}\right)$.

The classic heat transport governing equation is not given here but it is obviously taken into account considering latent heat of vaporization. At the wall surface, a convective heat transfer coefficient $h_{T}$ is specified and the short-wave radiative flux is considered via an absorptivity coefficient $\alpha$.

\section{Determination of the kinetics constant of the ISOBIO materials}

The time-dependent adsorption curves have been experimentally determined by gravimetric methods for CAV, BIO, OSB3 and CSB [14]. Regarding BCB, desorption experiments have been performed by an industrial partner (BCB). The characteristic diameter of the samples was of $4 \mathrm{~cm}$. 
If the sorption rate is slow compared to the vapor diffusive flux, the adjustments of 1D cylindrical calculations based on the local kinetics approach allow to determine the kinetic constant $k_{0}$. According to Reuge et al. [9], $k_{0}$ should be constant in the range of $20 \%$ to $70 \% R H$, for higher $R H, k_{0}$ tends to decrease because most of the sorption sites are already occupied. And actually, at $R H$ higher than $80 \%$, both local kinetics and diffusive mass transport are limiting phenomena [9]. Note that liquid diffusivity tends to usually initiate at $R H$ of about $60 \%$ and becomes really significant from $R H$ of about $80 \%$ as demonstrated in [18] and evidenced in the Fraunhofer Institute for Building Physics (FIBP) database. The 1D cylindrical calculations will be performed considering $\mu$ always equal to $\mu_{0}$ (as a first step) and ignoring the liquid diffusivities.

\subsection{CAVAC Rigid Panel}

\subsubsection{Experiments}

Initially, the samples have been stabilized at a given ambient $R H$, and then the $R H$ have been suddenly increased to a higher given value. For CAV, the following $R H$ steps have been tested: 0 $30 \% R H, 30-50 \% R H, 50-65 \% R H, 65-80 \% R H$ and $80-95 \% R H$. Regarding the $0-30 \% R H$ and $50-65 \% R H$ steps, one of the samples was weighted continuously, for the other steps the samples were weighed discontinuously [14]. Four representative samples were used for each measurement, the differences were lower than $5 \%$. The results of the measurements are shown in Figure 4: the stabilizations occur in more than 5 days. Note that regarding the $80-95 \%$ RH step, the measurements have been stopped before the stabilization because of initiation of mold development.

\subsubsection{D simulations}

First, 1D simulations based of the Künzel approach have been performed: for the $0-30 \% R H, 30-50 \%$ $R H, 50-65 \% R H$ steps, the times of stabilization are lower than 1 day and therefore greatly underestimated: this approach is invalidated (see Fig. 4 for the $30-50 \% R H$ step).

The adjustments of the 1D simulations based of the local kinetics approach leads to the following values of $k_{0}$ : $0.56,0.3,0.3,0.12$ and $0.08 \mathrm{day}^{-1} /\left(\mathrm{kg}^{-\mathrm{m}^{-3}}\right)$ for the $0-30 \% R H, 30-50 \% R H, 50-65 \% R H, 65-$ $80 \% R H$ and $80-95 \% R H$ steps respectively, as shown in Figure 4 . Therefore, as expected, $k_{0}$ is the same for $30-50 \% R H$ and $50-65 \%$ RH steps (i.e. inside the range of $20 \%$ to $70 \% R H$ ). The adjustments are globally very good with correlation coefficients greater than 0.99 . However, note that the simulations and the values of $k_{0}$ obtained for the $65-80 \% R H$ and $80-95 \% R H$ steps can be unreliable since the liquid diffusivity is not taken into account. As noticed in [9] for hemp concretes, at moderate $R H(<80 \%)$, the limiting parameter is $k_{0}$ and the calculation is insensitive to $\mu_{0}$. At high $R H$, both the kinetics and diffusive mass transport have an effect on the global sorption rate.

\subsection{Biofib Trio flexible}

The adjustments of the 1D simulations based of the local kinetics approach on adsorption curves [14] leads to the following values of $k_{0}: 20,9,13$ and 1.5 day $^{-1} /\left(\mathrm{kg}^{-\mathrm{m}^{-3}}\right)$ for the $30-50 \% R H, 50-65 \% R H, 65-$ $80 \% R H$ and $80-95 \% R H$ steps respectively (the $0-30 \% R H$ step measurements are too noisy to be exploited). Therefore, $k_{0}$ is around $14 \mathrm{day}^{-1} /\left(\mathrm{kg} \cdot \mathrm{m}^{-3}\right)$ at common $R H$ : this is a relatively high kinetic constant 


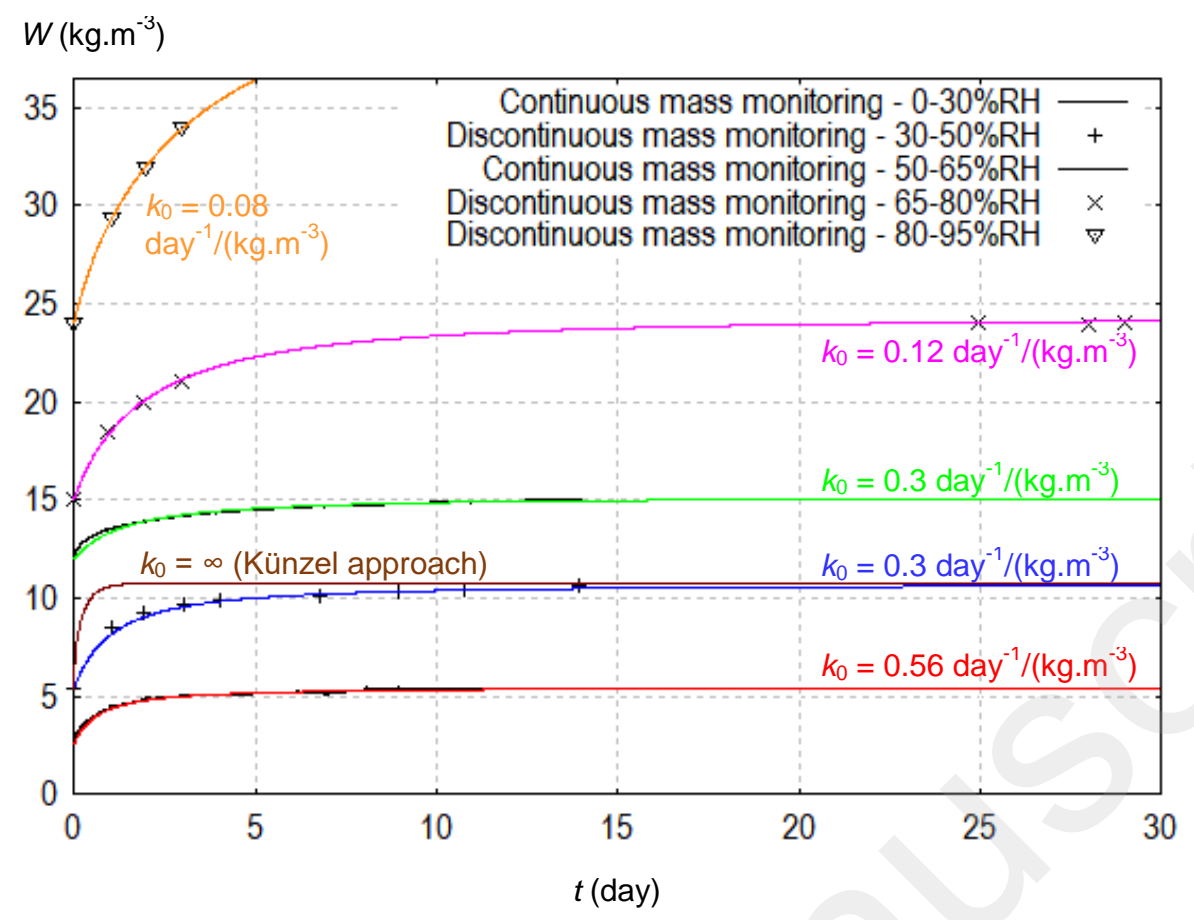

Figure 4: CAV sample - Adsorption measurements (symbols and black lines) - Adjusted 1D simulations (colored lines)

\subsection{CSB Lignicell panel}

This material is quite specific: it has a rather high $\mu_{0}$ of 27 and both kinetics and diffusive mass transport are limiting. From $50 \% R H$, both $k_{0}$ and $\mu$ have to be adjusted to obtain good agreements of the 1D simulations with the measurements. The adjustments showed in Figure 5 have been obtained with the following $k_{0}: 0.25,0.25,0.25,0.01$ and $0.001 \mathrm{day}^{-1} /\left(\mathrm{kg}^{-\mathrm{m}^{-3}}\right)$ and the following $\mu$ : 27 (i.e $\left.\mu_{0}\right)$, $27,22,8.5$ and 8.5 for the $0-30 \% R H, 30-50 \% R H, 50-65 \% R H, 65-80 \% R H$ and $80-95 \% R H$ steps respectively. Note that the value of 8.5 corresponds the apparent $\mu$ "humid" measured by Collet et al. [14] at $53-88 \% R H$.

\subsection{OSB3}

This material is also a particular case because its $\mu_{0}$ of 138 is so high that diffusive mass transport is the only limiting phenomena. This does not mean that no local kinetics exists but that the local kinetics is fast compared to the diffusive fluxes. Consequently, the Künzel approach is justified in this case. Performing 1D simulations based on this approach, a good agreement is obtained with the measurements adjusting $\mu$ to the following values: $275,100,100,40$ and 10 for the $0-30 \% R H, 30$ $50 \% R H, 50-65 \% R H, 65-80 \% R H$ and $80-95 \% R H$ steps respectively. The results are shown in Figure 6.

Note that the $\mu_{0}$ of 138 measured at $0-50 \% R H$ in [14] is indeed between 100 and 275 and that the measured $\mu$ "humid" (53-88\% $R H$ ) of 45 [14] is close to the adjustment value of 40 for the $65-80 \% R H$ step.

Under these conditions, the kinetic constant cannot be determined.

\subsection{BCB plaster}


This material has been roughly studied by an industrial partner $(B C B)$ in desorption conditions: 100$65 \% R H$ and $100-50 \% R H$. The adjustments of the 1D simulations based of the local kinetics approach

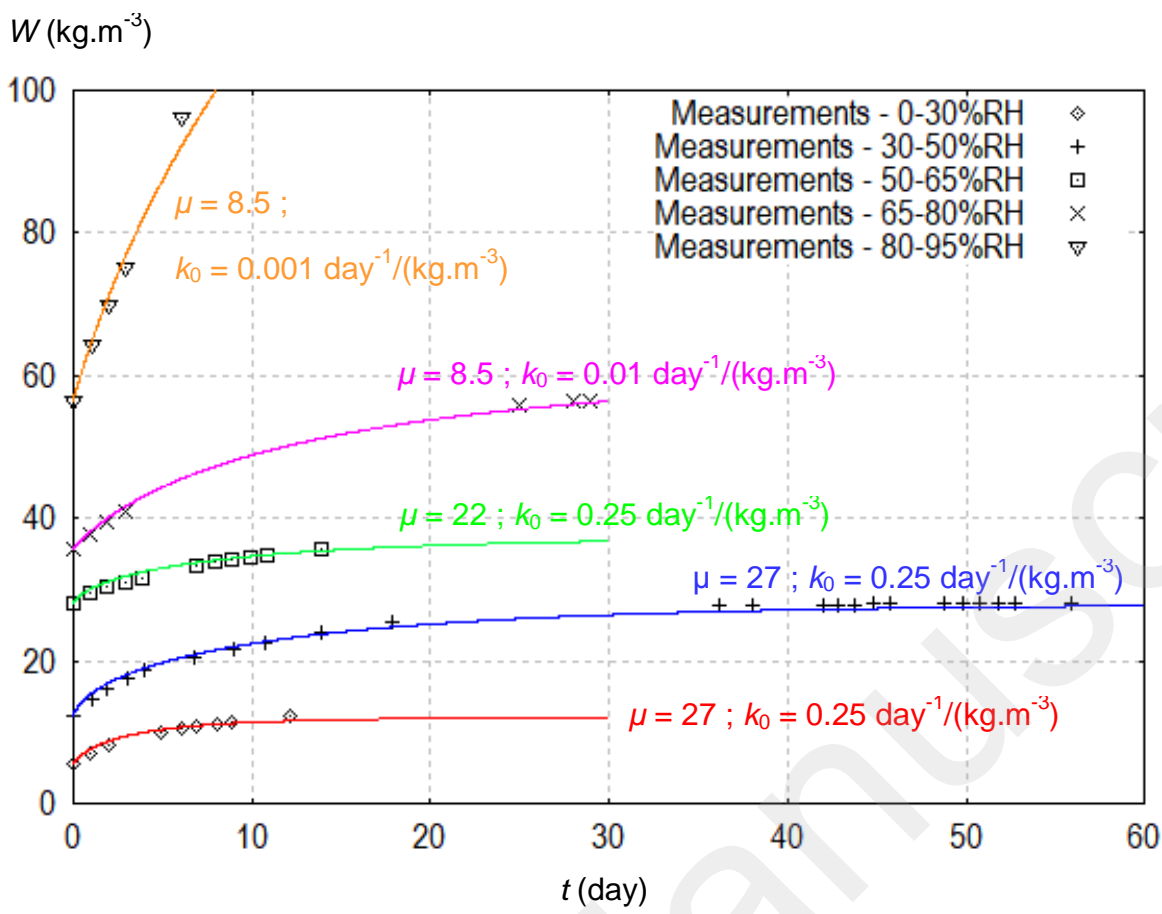

Figure 5: CSB sample - Adsorption measurements (symbols) - Adjusted 1D simulations (colored lines)

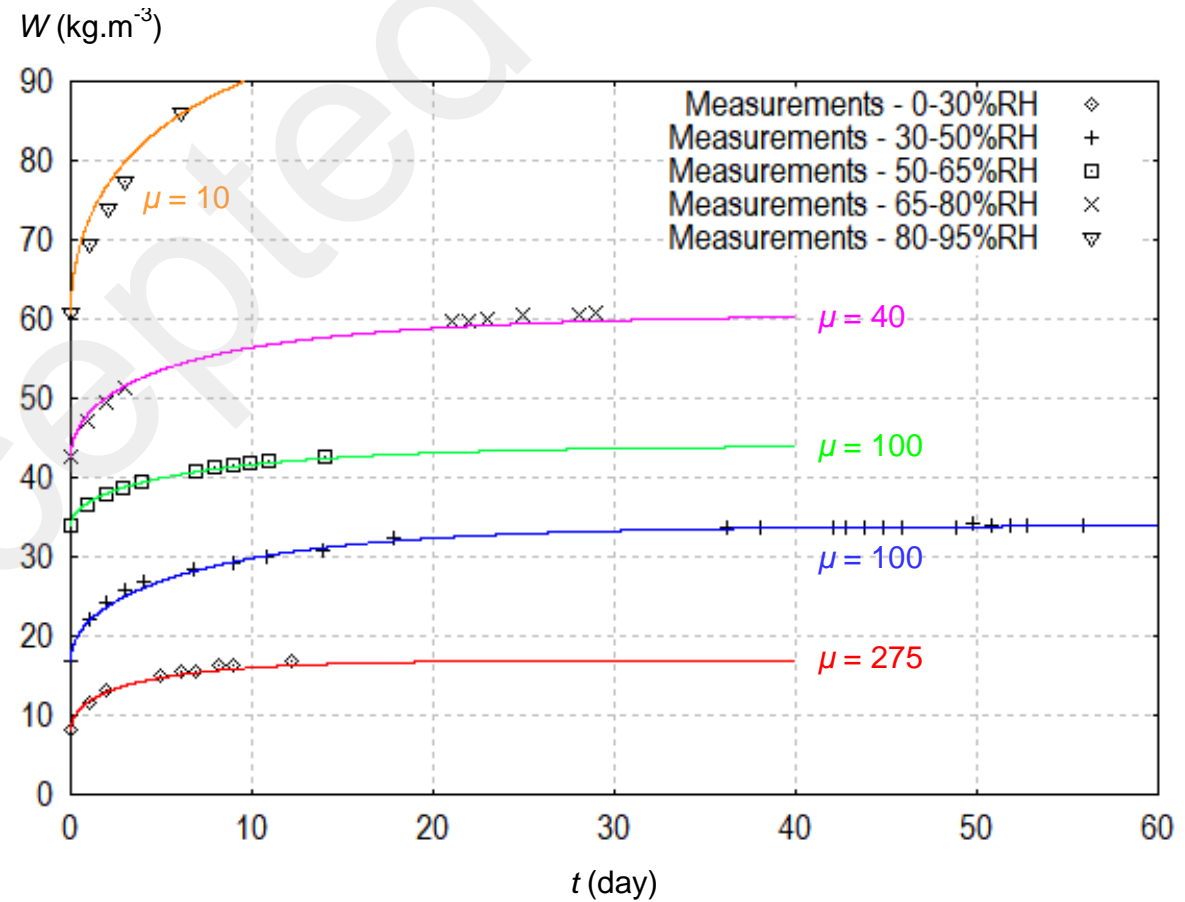

Figure 6: OSB3 sample - Adsorption measurements (symbols) - Adjusted 1D simulations (colored lines) 
lead to the following values of $k_{0}: 0.0045$ and $0.0055 \mathrm{day}^{-1} /\left(\mathrm{kg} \cdot \mathrm{m}^{-3}\right)$ for the $100-65 \% R H$ and $100-50 \%$ $R H$ steps respectively. Therefore, this is a quite slow kinetics constant of around $0.005 \mathrm{day}^{-1} /\left(\mathrm{kg}^{-3} \mathrm{~m}^{-3}\right)$; note that from [9], the kinetic constants of adsorption and desorption are the same (at least for the three hemp concretes studied in the cited study).

\subsection{Compilation of the kinetic constants}

From this study, in the $20-70 \% R H$ range, the kinetics constants $k_{0}$ can be very different according to the material: from $0.005 \mathrm{day}^{-1} /\left(\mathrm{kg} \cdot \mathrm{m}^{-3}\right)$ for BCB to about $14 \mathrm{day}^{-1} /\left(\mathrm{kg} \cdot \mathrm{m}^{-3}\right)$ for BIO, i.e. a difference of almost 4 orders of magnitude. The values determined for $R H$ greater than $80 \%$ are not reliable because the liquid diffusivities are unknown and have not been taken into account (see [9] for deeper explanations and investigations). For the simulations performed in the next section, the values of $k_{0}$ compiled in Table 4 will be considered. For the materials for which $k_{0}$ remains unknown, i.e. OSB3, INT and CLA, a median value of $0.25 \mathrm{day}^{-1} /\left(\mathrm{kg}^{\left.-\mathrm{m}^{-3}\right)}\right.$ will be considered; note that the thicknesses of the layers of these three materials in the reference ISOBIO wall are relatively small, particularly INT with $0.25 \mathrm{~mm}$ thickness and note that the value of $k_{0}$ of CLA is of minor importance when the $R H$ fluctuations at the indoor boundary conditions are almost non-existent (see section $5.2)$.

\begin{tabular}{|c|c|}
\hline & $\begin{array}{c}k_{0} \\
\left(\text { day }^{-1} /\left(\mathrm{kg}^{-3} \mathrm{~m}^{-3}\right)\right)\end{array}$ \\
\hline BCB & 0.005 \\
\hline CAV & 0.3 \\
\hline BIO & 14 \\
\hline OSB3 & $0.25^{*}$ \\
\hline INT & $0.25^{*}$ \\
\hline CSB & 0.25 \\
\hline CLA & $0.25^{*}$ \\
\hline
\end{tabular}

*Unknown, median value

Table 4: ISOBIO materials kinetic constants $k_{0}$

The good adjustments of the calculations on the measured sorption curves is in themselves a selfconsistent validation of the proposed kinetics approach. It should be emphasized that considering a kinetic order different from 2 would not lead at all to such good adjustments. And although lab-scale MBV (Moisture Buffer Value) test measurements had been performed in the framework of the ISOBIO project, at the moment they cannot serve as a second validation step of the kinetic approach for two reasons: for these experiments, (i) most hygric phenomena occur under the vicinity of the material surface and then are highly sensitive to the surface mass transfer coefficients which are extremely difficult to determinate precisely and (ii) by the fact that mass sample weight determinations (and then liquid content dynamics) are much less sensitive to the sorption kinetics than the relative humidity dynamics. Thus, the next part deals with in-situ $R H$ measurements performed in a demonstrator: this is arguably the most consistent approach.

Note that for CAV and BIO, the analytical expression given in [9] allow to straightly estimate $k_{0}$ without the need of performing simulations. 


\section{Simulations of the HIVE demonstrator}

In this final part, the hygrothermal behavior of the ISOBIO reference wall installed at the HIVE demonstrator (Wroughton, UK) is studied under the local climate during winter 2018. This consists in comparing the measurements and the simulations. To our knowledge, this is the first modeling work studying a multi-layered fully bio-based wall in real climatic conditions while various studies have already been carried out under controlled conditions and/or only one bio-based layer. Moujalled et al. [19] has studied the effect of real climatic conditions (Périgueux, FR) on a bio-based building with a wall of three layers: a hemp-lime concrete but with classic internal and external renders. Their simulations took into account the solar radiation and their results of the simulations were in globally good agreements with the measurements but the small time scale (on a few hours) $R H$ dynamics was very notably underestimated. Piot et al. [20] has also studied a three-layered wall (Savoie, FR) in real climatic conditions: a hemp concrete but also with classic internal and external renders. Again, the calculated small time scale $R H$ dynamics was very notably underestimated compared to the measurements. In $[21,22,23,24,25,26]$, the authors have studied the response of hemp concrete panels to controlled indoor and outdoor conditions. Even in these controlled operating conditions without solar radiation, most of these studies $[21,22,26]$ lead to simulation results that underestimate clearly the small time scale $R H$ dynamics. From that point of view, $[23,24,25]$ seem to obtain better results playing on some parameters which have an effect on the hysteretic behavior of the sorption phenomena such as the initial water content (which is usually unknown) or the considered hysteretic model.

\subsection{HIVE demonstrator: experimental setup}

The ISOBIO test wall dimensions were $1.95 \mathrm{~m} \times 1.95 \mathrm{~m} \times 33.45 \mathrm{~cm}$. Inside the demonstrator, a CS215 SDI12 Sensirion-based sensor was installed to measure air room $T$ and $R H$. Heating equipment was used to maintain a constant indoor air temperature (BioGreen Phoenix electrical resistance heater with inbuilt air circulation fan). Outside the demonstrator, a weather station was installed to measure: $R H$ and $T$ (Rotronic HC2S3 sensor within 9-element ventilated solar shield), the wind speed (2-axis Gill Instruments Ultrasonic anemometer), precipitation (RM Young Tipping Bucket rain gauge) and horizontal global and diffuse solar radiation (Delta T Devices SPN1 Sunshine Pyranometer). Three $R H$ and $T$ sensors were installed inside the wall (CS215) at:

- position 1: CAV / BIO1 interface,

- position 2: BIO1 / OSB3 interface,

- position 3: INT / BIO2 interface.

In standard operating conditions, the accuracy of the CS215 SDI-12 Sensirion sensor measurements is of $\pm 2 \% R H$ and $\pm 0.4^{\circ} \mathrm{C}$ for $T$.

Figure 7 presents the external view of the ISOBIO wall panel under test at the HIVE test facility. At the center of the external face of the test panel, the external surface temperature is measurement using a thermistor encapsulated in an epoxy-filled aluminum housing clipped to the surface of the BCB render. This sensor is protected in a solar shielded and ventilated space. Offset from the center of the panel, the first of three embedded CS215 RHT sensors is fixed the interface of CAV and BIO1, (i.e. position 1, approx. $75 \mathrm{~mm}$ from the external surface of the wall); the second CS215 RHT sensor is fixed at an approximate depth of $220 \mathrm{~mm}$ at the interface of BIO1 and the OSB3 board (position 2); and the third CS215 RHT sensor is at an approximate depth of $232 \mathrm{~mm}$ at the interface of the INT membrane and $\mathrm{BIO} 2$ (position 3). To avoid penetrations through the vapor control membrane, 
cabling for sensors between the membrane and the outer face of the test wall are routed to the outside and those inboard of the membrane are routed to the interior of the test enclosure.

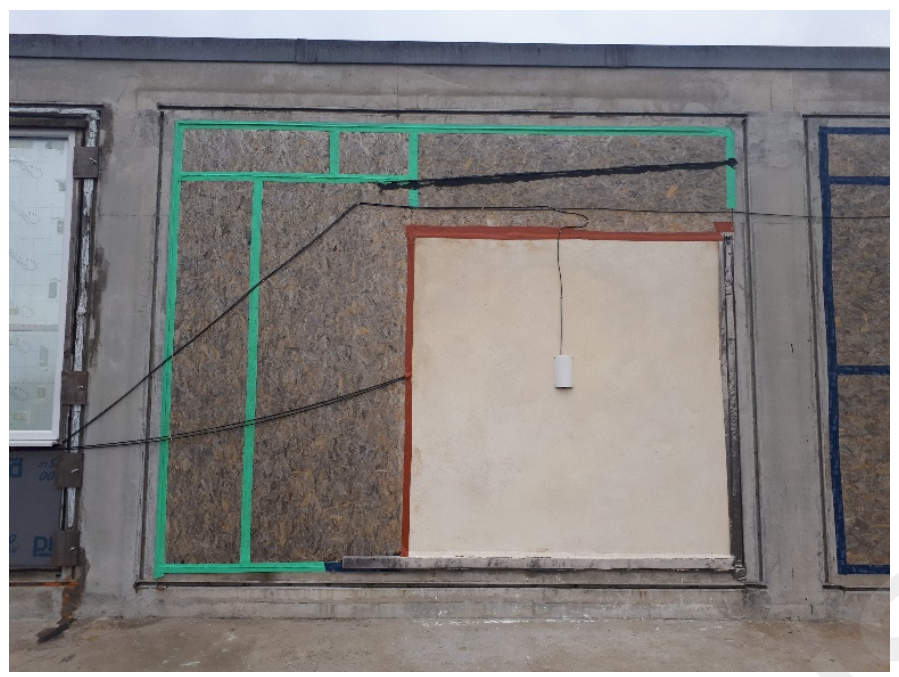

Figure 7: Outer face of the instrumented ISOBIO wall - HIVE demonstrator (Wroughton, UK)

\subsection{Boundary conditions}

The studied measurements have been performed during 18 days of winter 2018 (from 02/24 to $03 / 14$ ), i.e. during 432 hours. During this period, the indoor and outdoor $T$ and $R H$ measurements are shown in Figures $8 \mathrm{a}$ and $8 \mathrm{~b}$ respectively. As shown by these Figures, the climate was humid and cold, with outdoor $R H$ varying between $50 \%$ and $100 \%$ and outdoor $T$ varying between $-7^{\circ} \mathrm{C}$ and $12^{\circ} \mathrm{C}$. Solar short-wave radiation measurements are shown in Figure 9.

For the simulations, typical values have been considered for outdoor and indoor heat transfer coefficients, 17 and $8 \mathrm{~W} \cdot \mathrm{m}^{-2} \cdot \mathrm{K}^{-1}$ respectively $[27,28]$. A value of 0.4 has been considered for the white wall render (BCB) absorptivity $\alpha$ in accordance with RT2012 French standards [29]. For outdoor and indoor mass transfer coefficients, typical values of $7.4 \cdot 10^{-8}$ and $2.6 \cdot 10^{-8} \mathrm{~kg} \cdot \mathrm{Pa}^{-1} \cdot \mathrm{m}^{-2} \cdot \mathrm{s}^{-1}$ have been considered respectively $[27,28]$.
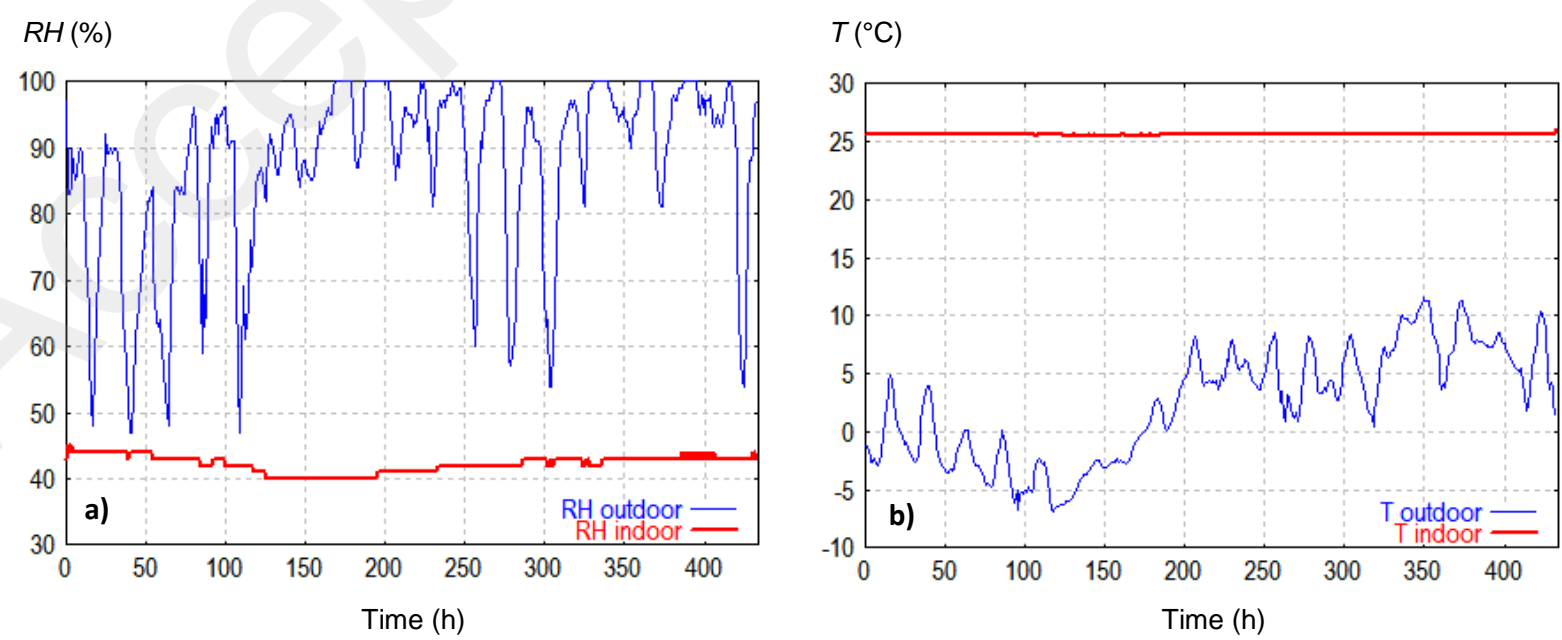

Figure 8: Indoor and outdoor $R H(\mathrm{a})$ and $T$ (b) measurements 


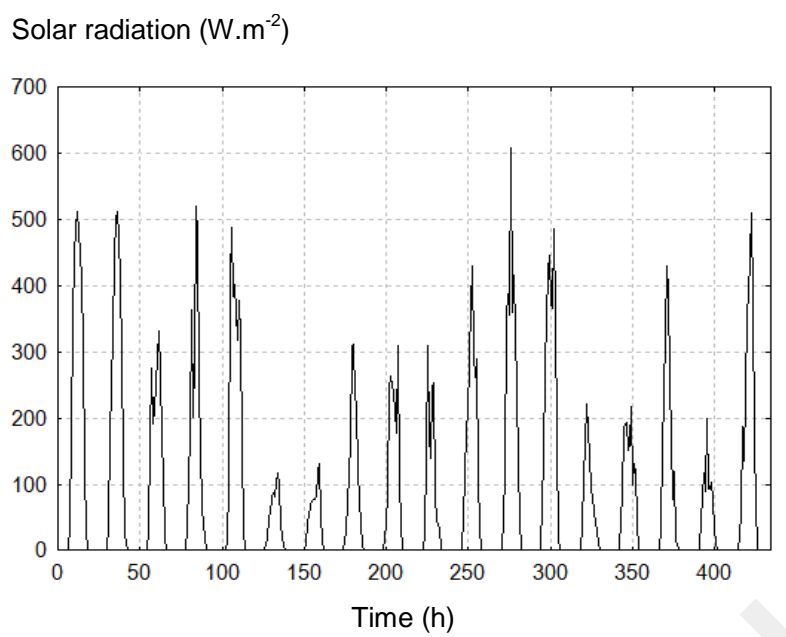

Figure 9: Solar short-wave radiation measurements

\subsection{Simulation tools}

Two simulation tools have been used:

- TMC, a home-made 1D Cartesian tool developed under Matlab based on the classic approach of Künzel,

- TMCKIN, a home-made 1D Cartesian tool developed under Matlab based on the local kinetics approach.

Note that TMC has been numerically validated on simple cases against WUFI ${ }^{\mathrm{TM}}$ 1D (a commercial tool) calculations.

\subsection{Assumptions}

For the mathematical models, assumptions are given in section 3.1. Regarding the sorption isotherms, the measurements done in adsorption conditions at $23^{\circ} \mathrm{C} \mathrm{(Fig.} \mathrm{2)} \mathrm{were} \mathrm{considered:}$ consequently, no temperature effect or hysteresis phenomena were considered. Constant vapor resistance factor coefficients at dry state $\mu_{0}$ were considered (Table 1 ) excepted for INT for which $\mu$ as a function of $R H$ was considered (Fig. 3). Liquid diffusivities were neglected. The effects of wind and rain and long-wave radiation on outdoor boundary conditions were neglected for the simulations.

For TMCKIN simulations, kinetics constants $k_{0}$ given in Table 4 were considered. As clearly demonstrated in (Reuge, 2019), the actual values of $k_{0}$ and of the liquid diffusivities of the bio-based materials are strongly interdependent at high $R H$ (>70-80\%). Since the liquid diffusivities associated with the ISOBIO materials are unknown, the most reasonable approach is to consider the values of $k_{0}$ constant even at high $R H$.

\subsection{Results of the simulations and discussion}

The initial hygrothermal conditions in the wall have been chosen as follow: 
- a constant $R H$ of $80 \%$ in each layer,

- water contents $w$ corresponding to $R H$ of $80 \%$ according to the sorption isotherm in each layer,

- a constant temperature $T$ of $10^{\circ} \mathrm{C}$.

Obviously, these initial conditions do not correspond to the reality. Consequently, an iterative procedure has been used: the first simulations (with TMC and TMCKIN) have been performed over a full cycle of 18 days considered the aforementioned initial conditions. A second set of simulations have been run considering as initial conditions the final profiles of $\varphi, w$ and $T$ in each layer inside the wall. Finally, a third set of simulations have been run considering as initial conditions the final hygrothermal profiles of the second simulations in each layer. Only the results of this third set of simulations will be presented here. It worth noting that this procedure does not guarantee that the third simulations were run with exactly the good initial conditions but at least that they were more realistic than the aforementioned constant values used for the first simulations.

The results of the simulations (TMC and TMCKIN) are given at the aforementioned positions. Figures 10a, 11a and 12a show the measured and calculated $R H$ over the full cycle (18 days) at pos. 1, 2 and 3 respectively. Figures $10 \mathrm{~b}, 11 \mathrm{~b}$ and $12 \mathrm{~b}$ show the measured and calculated $T$ at pos. 1,2 and 3 respectively. Broadly, the $R H$ obtained from the simulations are in good agreement with the measurements: the discrepancies are in a range of $\pm 4 \%$. Regarding the temperature evolutions, the agreements are good provided the solar radiations is taken into account, the peaks of temperature corresponding to intense solar radiation periods are almost perfectly reproduced.

Then, it is particularly interesting to analyze the dynamics of the $R H$ fluctuations at relatively small time scales (within at time interval of $24 \mathrm{~h}$ ): at pos. 1 (Fig. 10a) and pos. 2 (Fig. 11a), they are patently underestimated by the TMC if the solar radiation is not taken into account and better but still largely underestimated predicted by TMC if the solar radiation is taken into account. The dynamics is better predicted when the solar radiation is considered because the temperature peaks resulting from the radiative flux increase the variations of water vapor saturation pressure and then of $R H$. The best agreements are obtained with TMCKIN: this is a straight effect of the local kinetics delaying adsorption / desorption of the water vapor, this is particularly observable at pos. 1 and pos. 2 (Fig. 10a and 11a). Extracting the main $R H$ minima and maxima from the data, it is possible to estimate average $R H$ variations: at pos1, they are of 2.8, 0.84, 1.4 and 3.2 respectively from the measurements, the TMC simulation without solar radiation, the TMC simulation and the TMCKIN simulation. Thus, the TMC simulation (with solar radiation) underpredicts the $R H$ dynamics by $51 \%$ whereas the TMCKIN simulation slightly overpredict it by $12 \mathrm{bb} \%$. At this point, it must be reminded that the liquid water transport is ignored (because the liquid diffusivities are unknown for the studied materials) but its effect would undoubtfully soft the small time scale $R H$ dynamics at such high $R H$ of pos1. At pos2, the TMC simulation underpredicts the $R H$ dynamics by $56 \%$ whereas the TMCKIN simulation slightly overpredict it by $16 \%$. At pos3, the TMC simulation overpredicts the $R H$ dynamics by $11 \%$ and the TMCKIN simulation by $31 \%$ : the overpredictions at this last position are questionable. The measured and predicted $R H$ dynamics tend to be of a lesser extent at pos. 3 (Fig. 12a), this can be explained by the lesser effect of the solar radiation heat flux at such a deepness in the wall and by the filtering effect of the INT membrane on hygric variations.

Figure 13 shows the evolutions of local water content $w$ as a function of local relative humidity $\varphi$ at position 1 during the studied period of time (18 days) obtained with TMC and TMCKIN simulations. As expected, $(\varphi, w)$ moves along the sorption isotherm of CAV according to TMC simulation whereas $(\varphi, w)$ moves around it according to TMCKIN simulation. TMC simulation is always in an equilibrium 
hygric state, TMCKIN simulation only from time to time. Broadly, with TMCKIN, $\varphi$ evolves in a range of the equilibrium $\varphi \pm 4 \%$. Finally, as shown in Figure 14, the effect of consecutive cycles of the
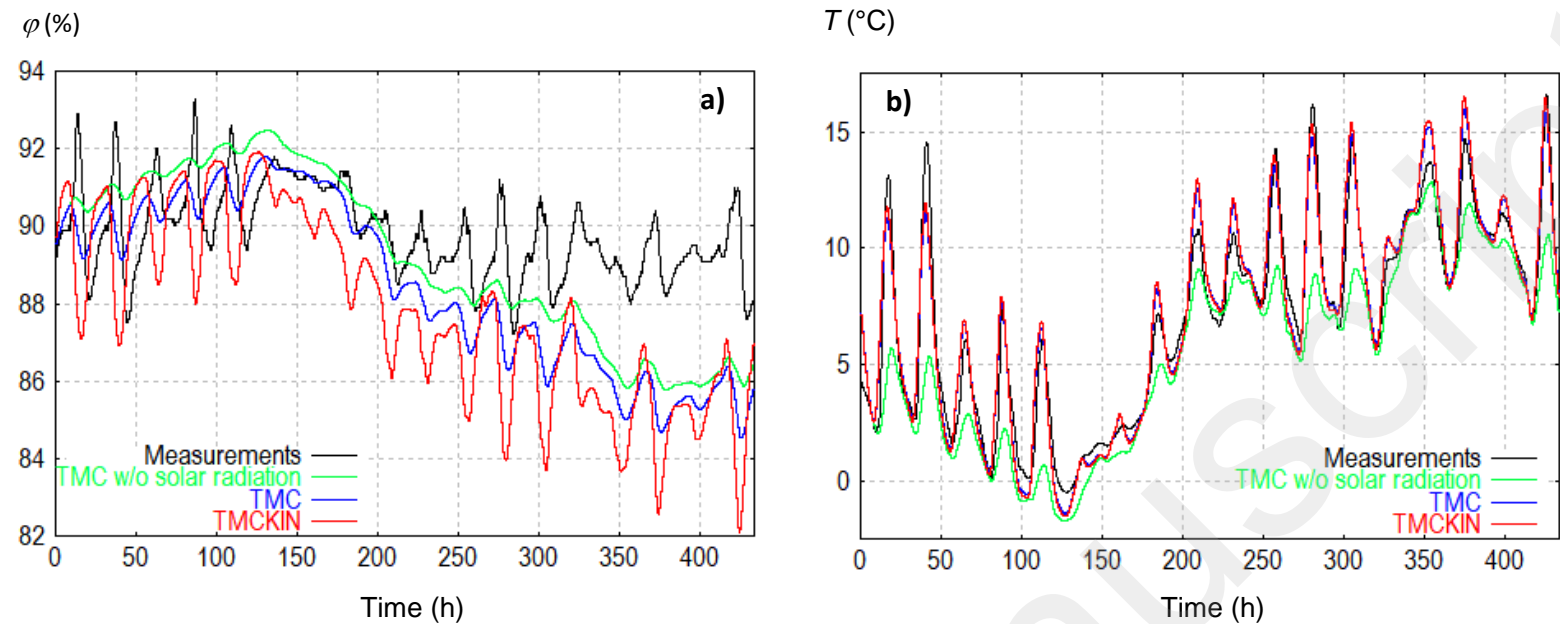

Figure 10: Measurements and simulations (TMC without solar radiation, TMC, TMCKIN) at position 1 - Temporal evolution of (a) relative humidity and (b) temperature
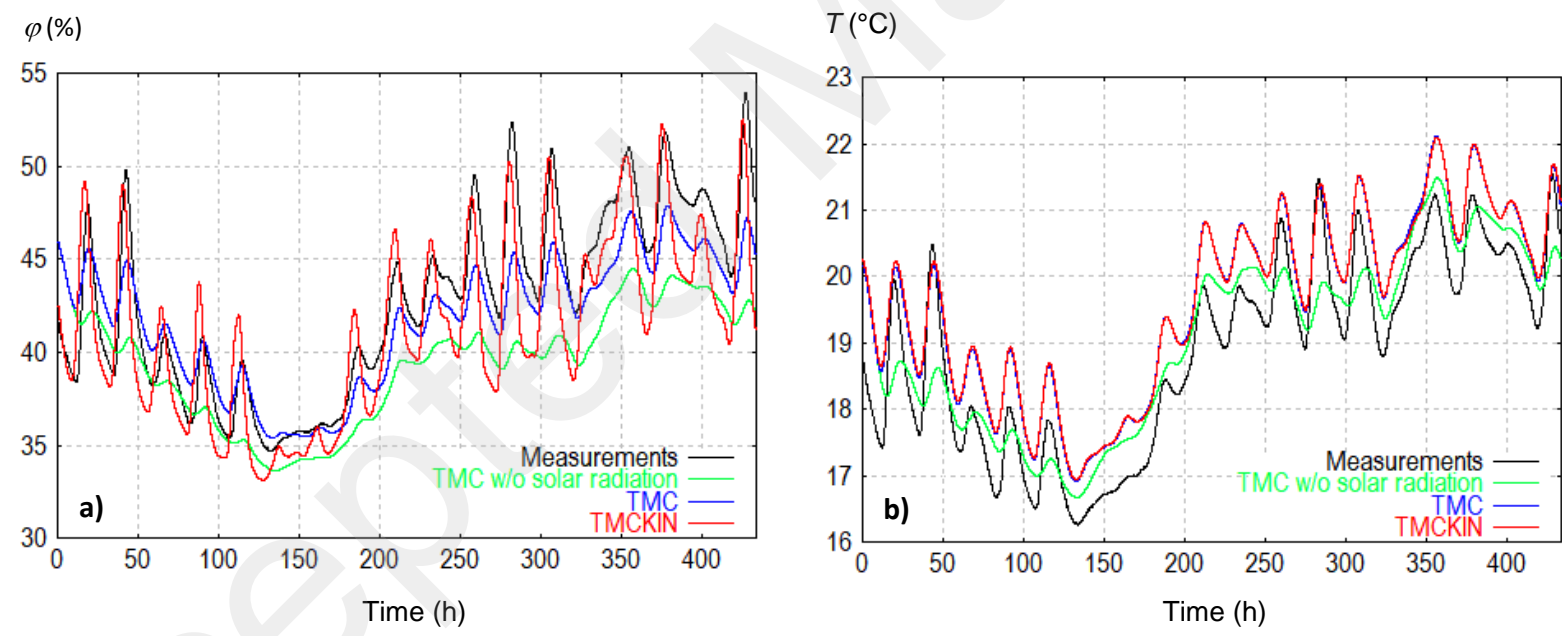

Figure 11: Measurements and simulations (TMC without solar radiation, TMC, TMCKIN) at position 2 - Temporal evolution of (a) relative humidity and (b) temperature

$\varphi(\%)$

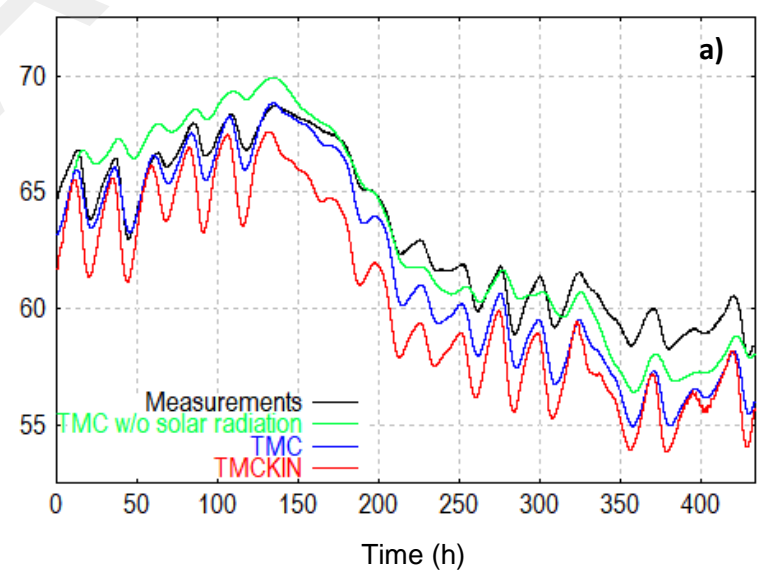

$T\left({ }^{\circ} \mathrm{C}\right)$

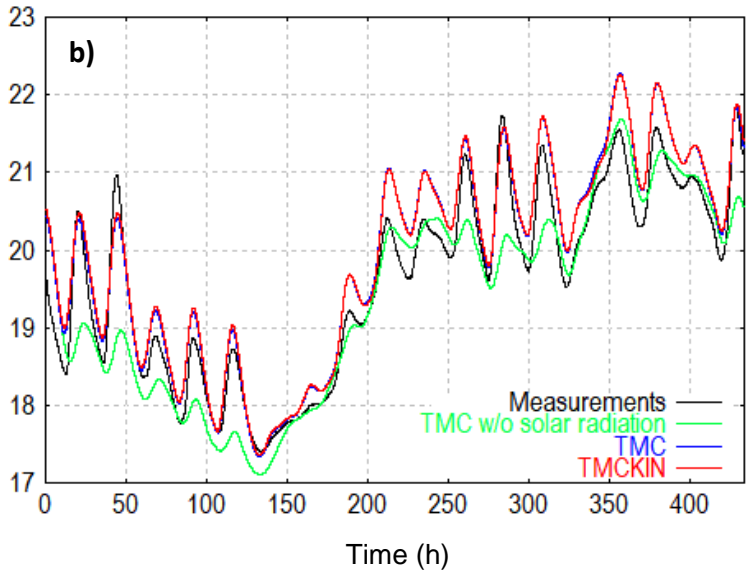


Figure 12: Measurements and simulations (TMC without solar radiation, TMC, TMCKIN) at position 3 - Temporal evolution of (a) relative humidity and (b) temperature

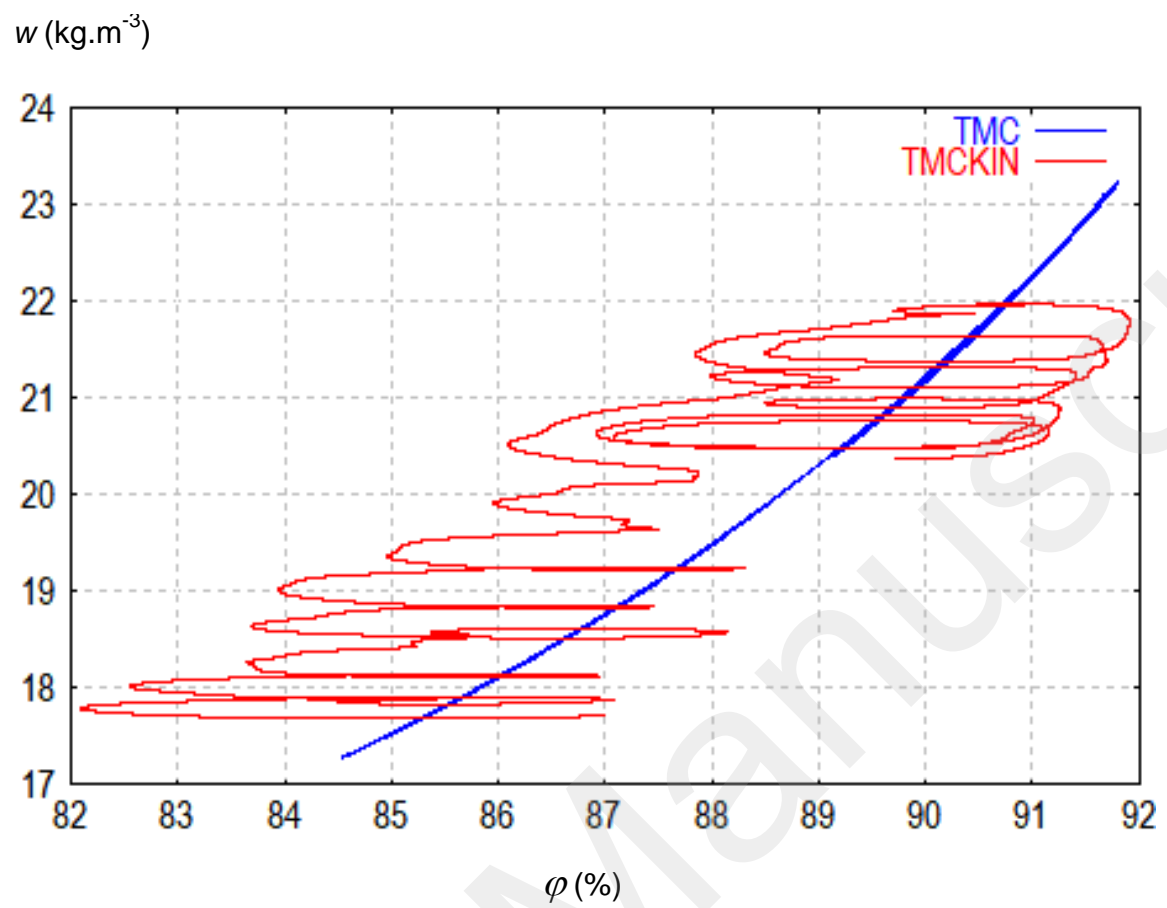

Figure 13: Evolution of local water content $w$ as a function of local relative humidity $\varphi$ at position 1 during the studied period of time (18 days) - TMC and TMCKIN simulations

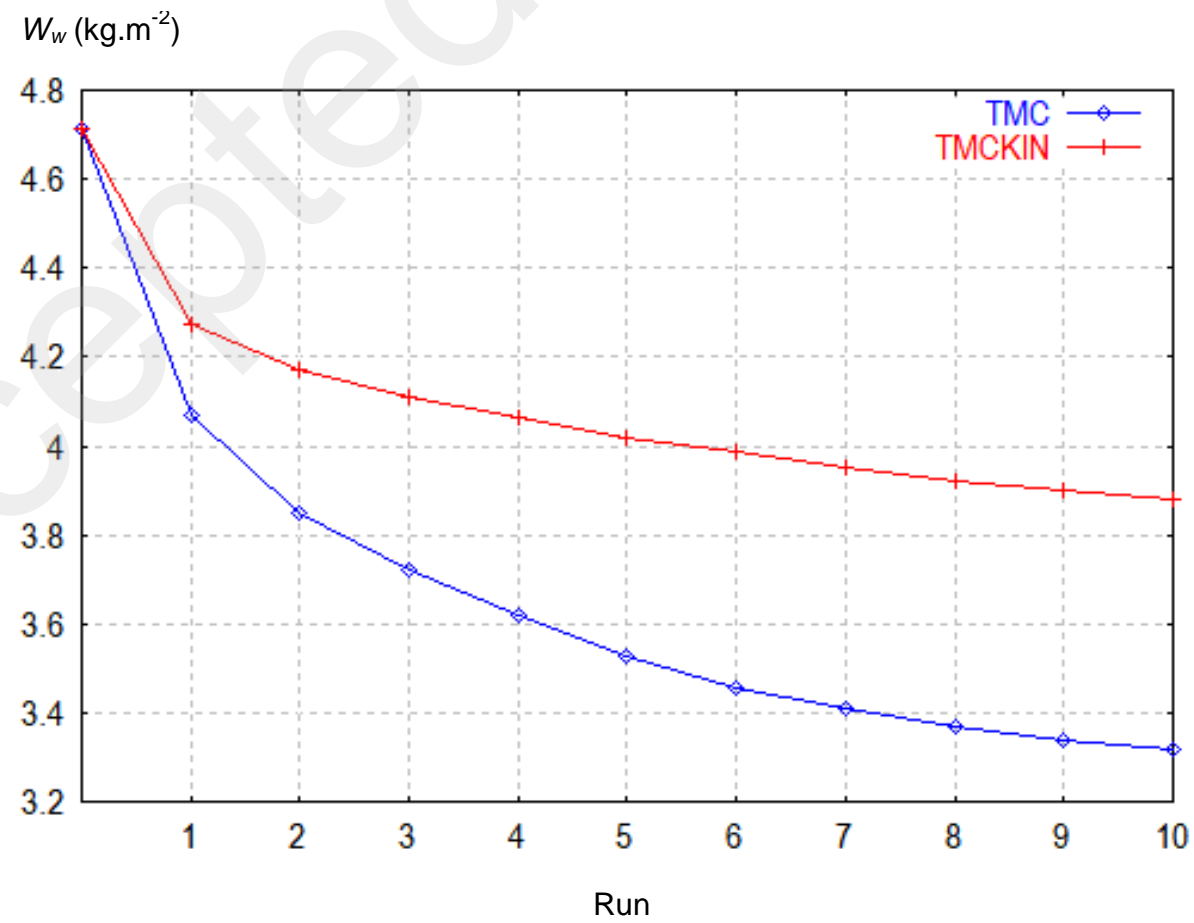


Figure 14: Total water content in the ISOBIO wall predicted after consecutive runs - TMC and TMCKIN simulations

considered 18 days is studied on the total wall water content considering every time the hygric state of the end of a run as initial conditions for the next run. This has been repeated 10 times with TMC and TMCKIN. Initially, the wall water content $W_{w}$ is of $4.71 \mathrm{~kg} \cdot \mathrm{m}^{-2}$. As aforementioned, the hygric state of the end of runs 2 had been considered as initial conditions for runs 3 which have been studied previously. From Fig. 14, the differences of $W_{w}$ predicted with TMC and TMCKIN doesn't cease to increase run after run. At the end of run 10, the predicted total wall water contents $W_{w}$ by TMC and TMCKIN are of $3.32 \mathrm{~kg} \cdot \mathrm{m}^{-2}$ and $3.88 \mathrm{~kg} \cdot \mathrm{m}^{-2}$ respectively, i.e. a difference as much as $17 \%$. Thus, after a long period of time, the hygric states of the wall predicted by TMC and TMCKIN can be very significantly different. It deserves to be emphasized, for instance in the perspective of durability studies.

\subsection{Sensitivity study}

It seems interesting to study the sensitivity of various intrinsic properties of the studied materials on the small time scale $R H$ fluctuations. The properties studied here are: the vapor resistance factor coefficient $\mu_{0} \pm 20 \%$, the kinetic constant $k_{0} \pm 20 \%$ and the thermal conductivity parameter $\lambda_{s} \pm 20 \%$. At a given position, the average $R H$ fluctuation obtained with TMCKIN is named $\overline{\Delta R H}$. The sensitivity $S$ of a given properties, for instance $\underline{\mu}_{0}$, on $\overline{\Delta R H}$ is given by:

$$
S=\frac{\overline{\Delta R H}\left(\mu_{0}+20 \%\right)-\overline{\Delta R H}\left(\mu_{0}-20 \%\right)}{0.4 \overline{\Delta R H}\left(\mu_{0}\right)}
$$

This means that if $\mu_{0}$ is modified by $x \%$, the predicted $\overline{\Delta R H}$ is modified by $x . S \%$ (at least in the range of $\left.\mu_{0} \pm 20 \%\right)$.

Three sensitivity studies have been performed:

- the first one varying the properties of the CAV layer,

- the second one varying the properties of the $\mathrm{BIO} 1$ and $\mathrm{BIO} 2$ layers,

- and the third one varying the properties of the INT layer.

For this last layer, only the $\mu_{0}$ parameter was tested (the other properties of this very thin layer do not impact the results of the simulations).

The values of the sensitivities $S$, at pos1, pos2 and pos3, are reported in Table 5. Note that when the calculated $S$ is lower than 0.01 , a dash has been reported instead of a value.

From these results, it appears that the sensitivity $S$ to the studied parameters is relatively low, i.e. taking into account the uncertainties given in Table 1 , the effect on $\overline{\Delta R H}$ is relatively limited and does not put into question the considerations of the previous section. That beeing said, the most sensitive parameter for $\mathrm{CAV}$ and $\mathrm{BIO} 1 / \mathrm{BIO} 2$ is $\mu_{0}$ and therefore must be measured very carefully. For INT, variations of $\mu_{0}$ in the $\pm 20 \%$ range does not have any effect, its value remains anyway too high.

In further investigations, the effect of the slopes of the isotherms of sorption can be analyzed, but this parameter is straightly linked with the effects of the hysteresis phenomena which is outside the scope of the present study. 


\begin{tabular}{|c|c|c|c|}
\cline { 2 - 4 } \multicolumn{1}{c|}{} & \multicolumn{3}{c|}{ Studied layer: CAV } \\
\cline { 2 - 4 } \multicolumn{1}{c|}{} & Pos1 & Pos2 & Pos3 \\
\hline$\mu_{0}$ & $-\mathbf{0 . 3 0 4}$ & 0.014 & - \\
\hline$k_{0}$ & -0.205 & - & - \\
\hline$\lambda_{s}$ & 0.194 & 0.127 & 0.159 \\
\hline \multicolumn{4}{|c|}{ Studied layers: BIO1 \& BIO2 } \\
\hline$\mu_{0}$ & $\mathbf{0 . 4 3 8}$ & 0.230 & 0.176 \\
\hline$k_{0}$ & 0.050 & -0.139 & -0.093 \\
\hline$\lambda_{s}$ & -0.073 & -0.028 & 0.084 \\
\hline & \multicolumn{3}{|c|}{ Studied layer: INT } \\
\hline$\mu_{0}$ & - & - & - \\
\hline
\end{tabular}

Table 5: Sensitivity study - Values of $S(-)$

\section{Conclusion}

This study has allowed to determine the kinetic constants of the key (on a hygric point of view) ISOBIO materials. According to these various materials, these kinetics constants can differ by four orders of magnitude. When the material vapor diffusion resistance factor $\mu_{0}$ is too high $(>100$, i.e. OSB3), the kinetic constant cannot be determined by the proposed 1D numerical method.

The simulations of the HIVE demonstrator have been performed and compared to the measurements. This is the first modeling study of a multi-layered bio-based wall and, despite some assumptions, the simulations have led to overall good agreements with the measurements. Regarding the heat transfers, taking into account the solar radiation is required to obtain accurate agreements on temperature with the in-situ measurements. Regarding the hygric transfer, it has appeared that taking account both the solar radiation and the kinetics of sorption (TMCKIN) are required to reasonably predict the small time scale (less than $24 \mathrm{~h}$ ) $R H$ dynamics. In the perspective of simulations of $R H$ variations inside a whole building, this work tends to show that the commercial simulation tools may fail to lead to reliable hygric results because they do not take into account the local kinetics effects.

In further investigations, the effects of an alternative climate and of internal $R H$ loads on the ISOBIO reference wall will be studied. Moreover, alternative configurations of the ISOBIO wall will be investigated.

\section{Acknowledgments}

This work has been performed and funded in the framework of the European project ISOBIO (http://isobioproject.com) within the scope the of the research and innovation program Horizon 
2020 (agreement No. 636835). This work has also been supported by the French region Bretagne Loire (UBL).

Special acknowledgments go to Prof. M. Lawrence (University of Bath) and Ronelvy Nivesse (BCB) for their works on the characterization of the $\mathrm{BCB}$ render.

\section{References}

[1] Kumaran, M.: Interlaboratory Comparison of the ASTM Standard Test Methods for Water Vapor Transmission of Materials (E 96-95). J. Test. Eval. 26(2), 83-88 (1998)

[2] Iglesias, H.A., Chirife, J.: Handbook of Food Isotherms: Water Sorption Parameters for Food and Food Components. Academic Press Inc., United Kingdom Edition (1982)

[3] Carmeliet, J., De Wit, M., Janssen, H.: Hysteresis and moisture buffering of wood. $7^{\text {th }}$ Nordic Symposium on Building Physics, Reykjavik, Islande (2005)

[4] Huang, H.C., Tan, Y.C., Liu, C.W., Chen C.H.: A novel hysteresis model in unsaturated soil. Hydrological Processes 19(8), 1653-1665 (2005)

[5] Perré, P., Challansonnex, A., Colin, J. : On the importance of heat and mass transfer coupling for the the characterization of hygroscopic insulation materials. Int. J. Heat Mass Transf. 133, 968-975 (2019)

[6] Nyman, U., Gustafsson, P.J., Johannesson, B., Hägglund, R.: Numerical method for the evaluation of non-linear transient moisture flow in cellulosic materials. Int. J. Numer. Meth. Engng 66, 1859$1883(2006)$

[7] Eitelberger, J., Svensson, S.: The sorption behavior of wood studied by means of an improved cup method. Transp. Porous Med. 92, 321-335 (2012)

[8] Alexandersson, M., Askfelt, H., Ristinmaa, M.: Triphasic model of heat and moisture transport with internal mass exchange in paperboard. Transp. Porous Med. 112, 381-408 (2016)

[9] Reuge, N., Moissette, S., Bart, M., Collet, F., Lanos, C.: Water transport in bio-based porous materials: A model of local kinetics of sorption-Application to tree hemp concretes. Transp. Porous Med. 128(2), 821-836 (2019)

[10] Johannesson, B., Nyman, U.: A numerical approach for non-linear moisture flow in porous materials with account to sorption hysteresis. Transp. Porous Med. 84, 735-754 (2010)

[11] Janssen, H., Albrecht Scheffler, G., Plagge, R.: Experimental study of dynamic effects in moisture transfer in building materials. Int. J. Heat Mass Transf. 98, 141-149 (2016)

[12] Zengh, Q., Xu, S.: A two-parameter stretched exponential function for dynamic water vapor sorption of cement-based porous materials. Mater. Struct. 50:128 (2017)

[13] Reuge, N., Moissette, S., Bart, M., Collet, F., Lanos C.: Modèle de cinétique locale de sorption couplé au phénomène d'hystérésis pour les matériaux biosourcés. RUGC 2018, 36 ${ }^{\text {ème }}$ Rencontres Universitaires de Génie Civil de l'AUGC, June 20th-22nd 2018, Saint Etienne, France (2018)

[14] Collet, F., Pretot, S., Colson, V., Gamble, C.R., Reuge, N., Lanos C.: Hygric propeties of materials used for ISOBIO wall solution for new buildings. 3rd International Conference on Bio-Based Building Materials, June 26th - 28th 2019, Belfast, UK (2019) 
[15] Van Genuchten, M.Th.:A closed-form equation for predicting the hydraulic conductivity of unsatured soils. Soil Science Society American Journal 4, 892-898 (1980)

[16] Collet, F.; Pretot, S.: Thermal conductivity of hemp concretes: Variation with formulation, density and water content. Building Materials 65, 612-619 (2014)

[17] Künzel, H.M.: Simultaneous Heat and Moisture Transport in Building Components - One- and Two-Dimensional Calculation Using Simple Parameters, Fraunhofer IRB Verlag Suttgart, ISBN 3-81674103-7 (1995)

[18] Oumeziane, Y.A.: Evaluation des performances hygrothermiques d'une paroi par simulation numérique : application aux parois en béton de chanvre. PhD thesis, Génie civil, INSA de Rennes (2013)

[19] Moujalled, B., Ouméziane, Y.A, Moissette, S., Bart, M., Lanos, C., Samri, D.: Experimental and numerical evaluation of the hygrothermal performance of a hemp lime concrete building: $A$ long term case study. Building and Environment 136, 11-27 (2018)

[20] Piot, A., Béjat, T., Bessette, L., Jay, A.: Hygrothermal behaviour of a hemp concrete wall: experimental and numerical study of coating. First International Conference on Bio-based Building Materials, June 22nd - 24th 2015, Clermont-Ferrand, France (2015)

[21] Lelievre, D., Colinart, T., Glouannec, P.: Hygrothermal behavior of bio-based building materials including hysteresis effects: Experimental and numerical analyses. Energy and Buildings 84,617-627 (2014)

[22] Colinart, T., Lelievre, D., Glouannec, P.: Experimental and numerical analysis of the transient hygrothermalbehavior of multilayered hemp concrete wall. Energy and Buildings 112, 1-11 (2016)

[23] Rahim, M., Tran Le, A.D., Douzane,O, Promis,G., Langlet, T.: Numerical investigation of the effect of non-isotherm sorption characteristics on hygrothermal behavior of two bio-based building walls. Journal of Building Engineering 7, 263-272 (2016)

[24] Colinart, T., Glouannec, P., Bendouma, M., Chauvelon, P.: Temperature dependence of sorption isotherm of hygroscopic building materials. Part 2: Influence on hygrothermal behavior of hemp concrete. Energy and Buildings 152, 42-51 (2017)

[25] Fabbri, A., McGregor, F.: Impact of the determination of the sorption-desorption curves on the prediction of the hemp concrete hygrothermal behaviour. Construction and Building Materials 157, 108-116 (2017)

[26] Seng, B., Lorente, S., Magniont, C.: Scale analysis of heat and moisture transfer through biobased materials - Application to hemp concrete. Energy and Buildings 155, 546-558 (2017)

[27] Schaube, H., Werner, H.: Wärmeübergangskoeffizient unter natürlichen Klimabedingungen. IBPMitteilung 13, Nr. 109 (1986)

[28] Erhorn, H., Szerman, M.: Überprüfung der Wärme- und Feuchteübergangskoeffizienten in Außenwandecken von Wohnbauten. Gesundheitsingenieur 113, H. 4, S. 177-186 (1992)

[29] RT 2012 - Règles Th-S : Caractérisation du facteur de transmission solaire des parois du bâtiment - CSTB Ed. (2015) 